\title{
Calculation of Right and Left Ventricular Ejection Fraction in Infants and Children by First Pass Radionuclide Angiocardiography Using Self-Synchronization Method
}

\author{
Tomoharu Akiba, Toru Ishihara, Masaru Yoshikawa, \\ Tetsuo Sato and Akio Komatani* \\ Department of Pediatrics and * Department of Radiology, \\ Yamagata University School of Medicine, Yamagata 990-23
}

\begin{abstract}
Akiba, T., Ishihara, T., Yoshikawa, M., Sato, T. and Komatani, A. Calculation of Right and Left Ventricular Ejection Fraction in Infants and Children by First Pass Radionuclide Angiocardiography Using Self-Synchronization Method. Tohoku J. exp. Med., 1983, 140 (4), 413-419 — First pass radionuclide angiocardiography was utilized to calculate right and left ventricular ejection fraction in $\mathbf{7 4}$ infants and children. For the synchronization of radionuclide imaging with the cardiac cycle, the peaks and valleys of corrected ventricular time activity curve were adopted as the time reference points instead of $R$ wave of electrocardiogram. Left ventricular ejection fractions obtained by the radionuclide technique correlated well with those derived from the contrast angiographic technique $(r=0.90)$, but right ventricular ejection fractions correlated less well $(r=0.74)$. This noninvasive technique appeared useful for evaluation of right and left ventricular ejection fraction. first pass radionuclide angiocardiography; selfsynchronization method; ejection fraction
\end{abstract}

Assessment of right and left ventricular function has traditionally necessitated invasive procedures such as cardiac catheterization and contrast ventriculography. Recently, radionuclide angiocardiography has widely been accepted as a clinically useful technique for the noninvasive assessment of both ventricular function. This technique is repeatable and useful for follow-up studies in nonhospitalized patients. Moreover, with the recent development of computer techniques, precision for analysis has been added and further broadened application has been made.

The ejection fraction is a useful indicacor for assessment of ventricular function. We performed first pass radionuclide angiocardiography in infants and children with various cardiac diseases, and calculated right and left ventricular ejection fractions. Our purpose is to evaluate the clinical usefulness of ejection fractions derived from the first pass radionuclide angiocardiography in comparison with those obtained from contrast ventriculography.

Received for publication, December 18, 1982. 


\section{Materials and Methods}

\section{Patients}

Seventy-four patients, 42 boys and 32 girls, with mean age of 4 years (ranged from 6 months to 12 years) were studied; 25 with Kawasaki disease, 8 with cardiomyopathy, 1 with Bland-White-Garland syndrome, 5 with aortic stenosis, 1 with aortic regurgitation, 2 with mitral regurgitation, 5 with pulmonary stenosis, 3 with pulmonary regurgitation and 24 with postoperative condition.

Left ventricular ejection fractions were calculated in all patients, and right ventricular ejection fractions were in 22 of them.

\section{Radionuclide data acquisition}

Data acquisition was performed with a gamma camera (Ohjo-Nuclear $\sum 410 \mathrm{~S}$ ) equipped with a slant hole collimator and these data were stored on a computer system (DEC, PDP-11/34, 128kB). The patient was placed in a $30^{\circ}$ right anterior oblique position or in a modified $45^{\circ}$ left anterior oblique position. A 22 -gauge indwelling teflon venous sheath was inserted in an antecubital vein or a superficial dorsal vein of the hand, and 10 to $20 \mathrm{mCi}$ of technetium $-99 \mathrm{~m}$ sodium pertechnetate was given as a bolus injection followed by 5 to $10 \mathrm{ml}$ of saline solution. Precordial activity was recorded during the first circulation through the heart. Data were accumulated at 20 to $30 \mathrm{msec}$ intervals and the whole process was completed within 10 to 15 sec. These were framed at 20 frames/sec in a $64 \times 64$ matrix.

\section{Radionuclide data processing}

After a data acquisition, the time activity curves were generated about the regions of interest of the right and left ventricles (Fig. 1). However, it was difficult to determine the end-diastolic and end-systolic points in these curves, since the component of volume curve due to cardiac construction were overlapped with the dilution curve produced by passing of tracers. To remove the misleading of the end-diastolic and end-systolic points, the value

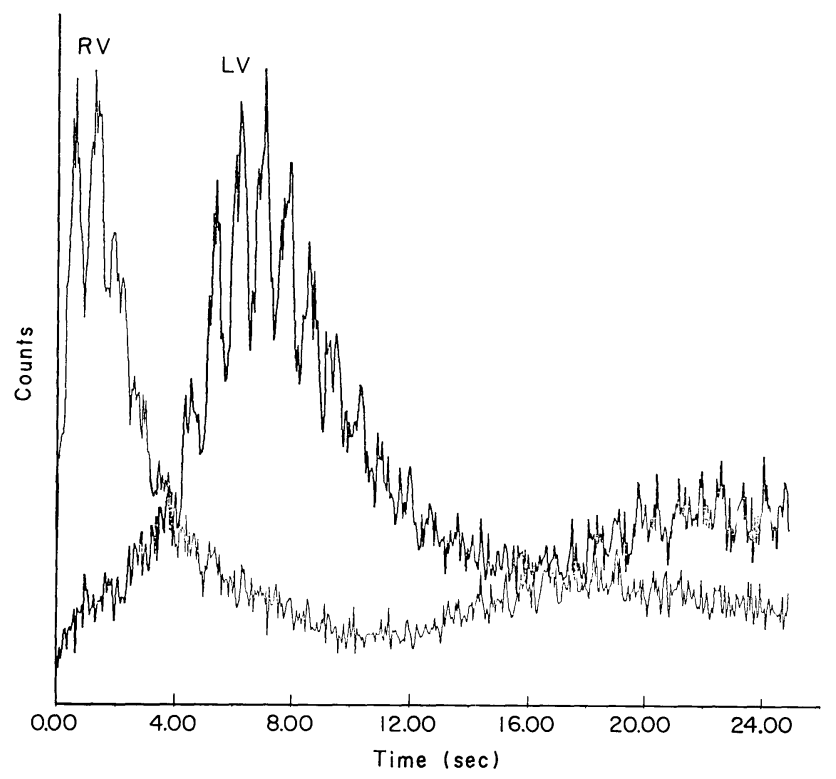

Fig. 1. Typical right ventricular $(\mathrm{RV})$ and left ventricular $(\mathrm{LV})$ time activity curves. 


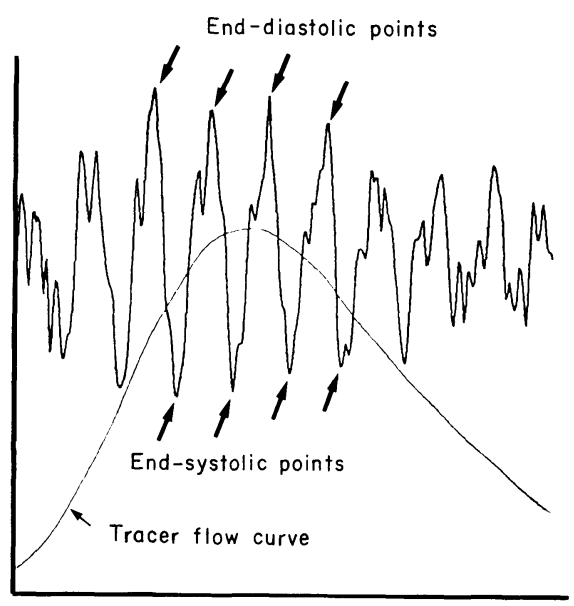

Fig. 2. Typical corrected left ventricular time activity curve.

of the original time activity curve was divided by the value of the tracer flow curve which derived from smoothing of the original curve, then the corrected time activity curve was obtained (Fig. 2). The peaks and valleys of the curve corresponded to the end-diastolic and end-systolic points respectively, which were adopted as the time reference points for synchronization instead of $\mathrm{R}$ wave of electrocardiogram. This method was named "selfsynchronization" (Komatani et al. 1981). By means of this method, frames of five or more cardiac beats were superimposed in synchronization with the cardiac phase using the both points of end-diastole and end-systole for construction of a closed-loop movie format. Based on this format, right and left ventricular ejection fractions were calculated. For tracing of the borders, the tricuspid and pulmonary valve plane in the right cardiac cavity and mitral and aortic valve plane in the left one were first identified with a joy stick system. Then, the edge-detection within noncardiac structure was performed using the isocount line of $30 \%$ in the right ventricle and $50 \%$ in the left ventricle of the maximum intraventricular counts on the end-diastolic frame.

In order to correct the interference by radioactivity of noncardiac structure, regions of interest for background subtraction were assigned as semiannular rings which surround the ventricles on the end-diastolic frame avoiding radioactivity of the great vessels and atria. Ejection fractions were calculated according to the following formula:

$$
E F=\frac{E D c-E S c}{E D c-B G c}
$$

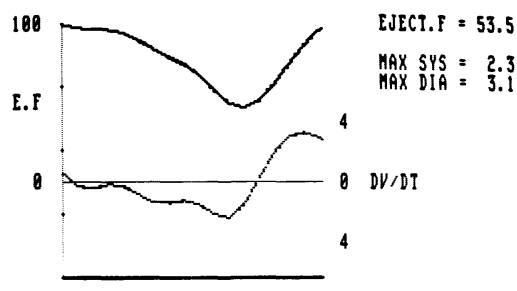

HEART RATE $=78.9$

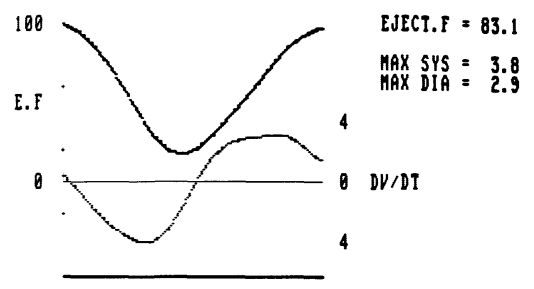

HEART BATE $=78.9$

Fig. 3. Right (left panel) and left (right panel) ventricular volume curve and $\mathrm{d} V / \mathrm{d} T$ curves from an 8-year-old boy with cardiomyopathy. 
where $E F=$ ejection fraction, $E D c=$ end-diastolic counts, $E S c=$ end-systolic counts and $B G c$ =background counts.

Right and left ventricular volume curves and $\mathrm{d} V / \mathrm{d} T$ curves were generated simultaneously (Fig. 3).

\section{Contrast ventriculographic analysis}

Within two weeks of radionuclide studies, each patient underwent right and left ventriculograms. Both ventricular cineangiograms were recorded on $35 \mathrm{~mm}$ films at 50 frames/sec in the biplane frontal and lateral projections following intraventricular injection of $0.7-1.0 \mathrm{ml} / \mathrm{kg}$ of $76 \%$ meglumine and sodium amidotrizoate (Urografin 76 ) over $0.5-1.0$ sec. End-diastolic and end-systolic frames of the cineangiograms were visually selected. The outlines of ventricular cavities were traced from these frames in both frontal and lateral projections with a $35 \mathrm{~mm}$ viewing screen (Vanguard $35-\mathrm{XR}$ ). Beats preceded or followed by premature ventricular contraction were avoided. Ventricular volumes were calculated using the Simpson's rule method described by Chapman et al. (1958). Ejection fractions were calculated according to the following formula:

$$
E F=\frac{E D V-E S V}{E D V}
$$

where $E F=$ ejection fraction, $E D V=$ end-diastolic volume and $E S V=$ end-systolic volume.

\section{RESULTS}

Right ventricular ejection fractions averaged $51 \pm 12 \%$ (range 33 to $81 \%$ ). In Fig. 4, contrast ejection fractions were plotted against radionuclide ejection fractions for 22 patients. The correlation coefficient was 0.74 . The regression equation for these data $(Y=0.80 X+6.41)$ indicated that the radionuclide ejection fractions were about $5 \%$ lower in average than the contrast ejection fractions.

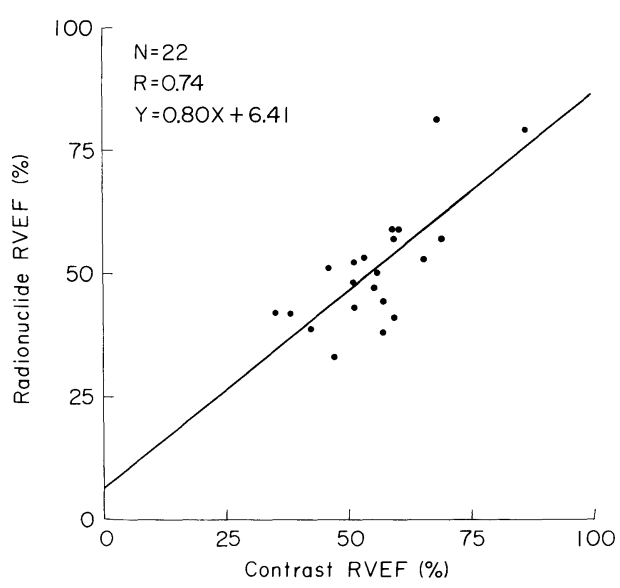

Fig. 4

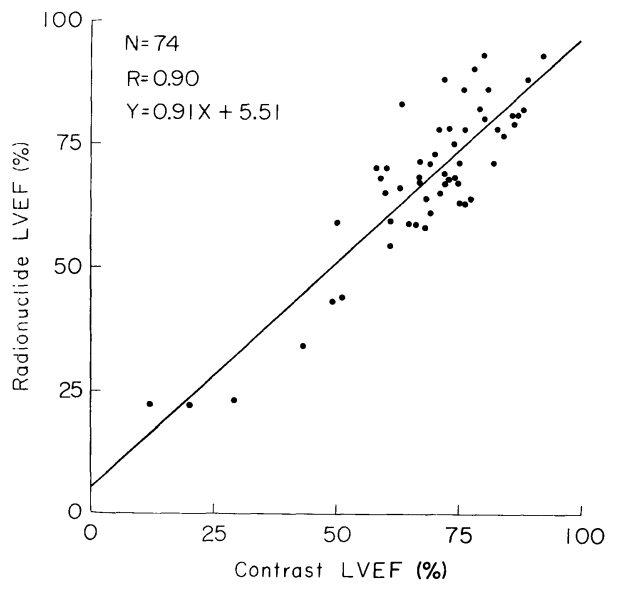

Fig. 5

Fig. 4. Correlation between right ventricular ejection fraction measured by radionuclide and contrast angiography.

Fig. 5. Correlation between left ventricular ejection fraction measured by radionuclide and contrast angiography. 
Left ventricular ejection fractions averaged $68 \pm 17 \%$ (range 17 to $93 \%$ ) in 74 patients. These results were compared to ejection fractions determined from contrast cineangiograms (Fig. 5). There was an excellent correlation $(r=0.90)$ between these ejection fractions obtained with both techniques.

\section{Discussion}

There are two methods for radionuclide imaging technique, one is the first pass method (Marshall et al. 1977; Berger et al. 1978; Hecht et al. 1978; Jengo et al. 1978; Olvey et al. 1980) and the other is the gated equilibrium blood-pool method (Burow et al. 1977; Maddox et al. 1978; Maddahi et al. 1979; Wackers et al. 1979; Holman et al. 1981). Each method has some intrinsic advantages and disadvantages. The gated equilibrium blood-pool method, with a single injection of radioisotope, permits repeated studies and an assessment of cardiac anatomy from multiple angles of view. However, the demerit of this method is the overlapping of cardiac chambers due to simultaneous visualization of all chambers. On the other hand, the first pass method permits temporal and anatomic separation of radioactivity in the right and left heart structures.

For the synchronization at radionuclide imaging, $\mathrm{R}$ wave of electrocardiogram has been traditionally employed. However, we adopted the peaks and valleys of the ventricular time activity curve as the time reference points for the synchronization instead of $\mathrm{R}$ wave in the electrocardiographic gating, and thereby enddiastolic and end-systolic points could be selected. Because these two points were employed as the time reference for the synchronization in this method, clear cine mode display could be obtained in patients not only with regular rhythm but with arrhythmia. Therefore, our method was particularly useful in infants and children, since many of them presented respiratory arrhythmia.

Ejection fraction was obtained by analysis of time activity curves generated during the first passage of the radionuclide bolus through the right or left ventricles. This count-based technique does not depend on a variation in ventricular geometry, and therefore it is particularly suitable for measuring the right ventricular ejection fraction. However, the major problem of this technique is the appropriate correction for background activity. Schelbert et al. (1975) reported that left ventricular ejection fraction correlated best with the contrast angiographic results when a semiannular region of interest was utilized for the correction of background activity. In calculating right ventricular ejection fraction, background counts originating from the pulmonary vascular bed were relatively low. In our studies, the semiannular rings surrounding the both ventricles were assigned to background regions of interest.

In the present study, left ventricular ejection fractions obtained from the radionuclide technique correlated well with those derived from the contrast technique $(r=0.90)$, but right ventricular ejection fractions correlated less well $(r=0.74)$. For this reason, in calculating right ventricular ejection fraction, only 
two or three cardiac cycles were adopted for analysis because of presenting tachycardia in many patients and rapid passage of radionuclide bolus through the right cardiac cavity. Therefore, the precision for estimation of right ventricular ejection fraction may be slightly inferior to that of left ventricular ejection fraction. Recently, it was reported that Kr-81 m (Knapp et al. 1980) or Xe-133 (Goldberg et al. 1981) were suitable agents for obtaining an adequate information density in right ventricular image analysis.

First pass radionuclide angiocardiography using "self-synchronization" in infants and children appeared to be a useful tool for evaluation of the right or left ventricular ejection fraction in our experience. However, further improvement is necessitated to obtain more accurate information, particularly in the estimation of right cardiac function.

\section{Acknowledgment}

We wish to thank Prof. Tadashi Hayashi, Department of Pediatrics, Yamagata University School of Medicine, for his advice and criticism in preparing the manuscript.

\section{References}

1) Berger, H.J., Matthay, R.A., Marshall, R.C., Gottschalk, A. \& Zaret, B.L. (1978) Assessment of cardiac performance with quantitative radionuclide angiocardiography: right ventricular ejection fraction with reference to finding in chronic obstructive pulmonary disease. Amer. J. Cardiol., 41, 897-905.

2) Burow, R.D., Strauss, H.W., Singleton, R., Pond, M., Rehn, T., Bailey, I.K., Griffith, L.C., Nickoloff, E. \& Pitt, B. (1977) Analysis of left ventricular function from multiple gated acquisition cardiac blood pool imaging. Comparison to contrast angiography. Circulation, 56, 1024-1028.

3) Chapman, C.B., Baker, O., Reynolds, J. \& Bonte, F.J. (1958) Use of biplane cinefluorography for measurement of ventricular volume. Circulation, 18, 1105-1117.

4) Goldberg, M.J., Mantel, J., Friedin, M., Ruskin, R. \& Rubenfire, M. (1981) Intravenous Xenon-133 for the determination of radionuclide first pass right ventricular ejection fraction. Amer. J. Cardiol., 47, 626-630.

5) Hecht, H.S., Mirell, S.G., Rolett, E.L. \& Blahd, W.H. (1978) Left-ventricular ejection fraction and segmental wall motion by peripheral first-pass radionuclide angiography. J. nucl. Med., 19, 17-23.

6) Holman, B.L., Wynne, J., Zielonka, J.S. \& Idoine, J.D. (1981) A simplified technique for measuring right ventricular ejection fraction using the equilibrium radionuclide angiocardiogram and the slant-hole collimator. Radiology, 138, 429-435.

7) Jengo, J.A., Mena, I., Blaufuss, A. \& Criley, J.M. (1978) Evaluation of left ventricular function (ejection fraction and segmental wall motion) by single pass radionuclide angiography. Circulation, 57, 326-332.

8) Knapp, W.H., Helus, F., Lambrecht, R.M., Elfner, R., Gasper, H. \& Vollhaber, H. (1980) $\mathrm{Kr}-81 \mathrm{~m}$ for determination of right ventricular ejection fraction (RVEF). Europ. J. nucl. Med., 5, 487-492.

9) Komatani, A., Takamiya, M., Takahashi, K. \& Yamaguchi, K. (1981) Radio nuclide cardiac examination with "self-synchronization" - The new method without ECG gating -. Jap. J. nucl. Med., 18, 315-321. (in Japanese with English abstract)

10) Maddahi, J., Berman, D.S., Matsuoka, D.T., Waxman, A.D., Stankus, K.E. \& Forrester, J.S. (1979) A new technique for assessing right ventricular ejection fraction using rapid multiple-gated equilibrium cardiac blood pool scintigraphy. Circulation, 60, 581-589. 
11) Maddox, D.E., Holman, B.L., Wynne, J., Parker, J.A., Uren, R., Neill, J.M. \& Cohn, P.F. (1978) Ejection fraction image: A noninvasive index of regional left ventricular wall motion. Amer. J. Cardiol., 41, 1230-1238.

12) Marshall, R.C., Berger, H.J., Costin, J.C., Freedman, G.S., Wolberg, J., Cohen, L.S., Gottschalk, A. \& Zaret, B.L. (1977) Assessment of cardiac performance with quantitative radionuclide angiocardiography. Sequential left ventricular ejection fraction, normalized left ventricular ejection rate, and regional wall motion. Circulation, 56, 820-829.

13) Olvey, S.K., Reduto, L.A., Stevens, P.M., Deaton, W.J. \& Miller, R.R. (1980) First pass radionuclide assessment of right and left ventricular ejection fraction in chronic pulmonary disease. Effect of oxygen upon exercise response. Chest, 78, 4-9.

14) Schelbert, H.R., Verba, J.W., Johnson, A.D., Brock, G.W., Alazraki, N.P., Rose, F.J. \& Ashburn, W.L. (1975) Nontraumatic determination of left ventricular ejection fraction by radionuclide angiocardiography. Circulation, 51, 902-909.

15) Wackers, F.J. Th., Berger, H.J., Johnstone, D.E., Goldman, L., Reduto, L.A., Langou, R.A., Gottschalk, A. \& Zaret, B.L. (1979) Multiple gated cardiac blood pool imaging for left ventricular ejection fraction: Validation of the technique and assessment of variability. Amer. J. Cardiol., 43, 1159-1166. 